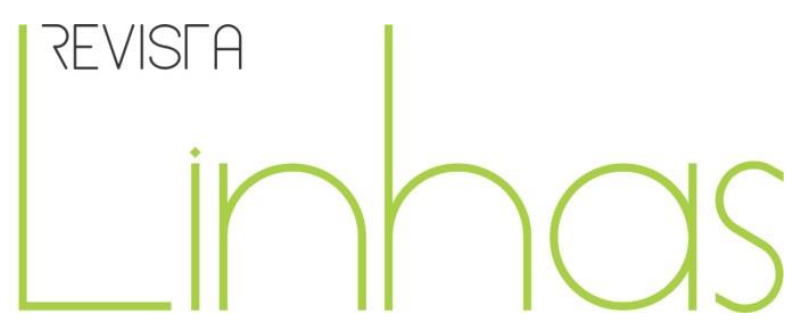

\title{
Família homoparental: enfrentando a vitalidade do patriarcado
}

\section{Resumo}

Descreve-se o desenvolvimento da família homoparental no Brasil em confronto com a preservação e conservação do patriarcado culturalmente instalado desde o descobrimento do país. Priorizaramse pesquisas e dados estatísticos brasileiros como elementos estruturadores da respectiva descrição. Trata-se de pesquisa bibliográfica de abordagem qualitativa. As fontes são 25 documentos produzidos de 2009 a 2015. Os dados dizem respeito: à ambientação que antecedeu a família homoparental, ao cenário de violência no qual se assenta a família homoparental e a algumas incursões sobre a contribuição da escola na produção de preconceitos e na conservação do patriarcado. Assim, e neste caso, apesar dos avanços legais indicarem a construção de um ambiente de convivência social justo e igualitário para as pessoas homoafetivas e para as famílias homoparentais, a sociedade brasileira está longe de operacionalizálos de fato e de direito. A hegemonia ainda é do patriarcado, mas sua vitalidade também está sendo colocada à prova.

Palavras-chave: Patriarcado. Família Homoparental. Violência. Escola.

\author{
João Guilherme de Carvalho Gattás \\ Tannuri \\ Universidade Estadual Paulista Júlio \\ de Mesquita Filho - UNESP - Rio \\ Claro/SP - Brasil \\ guigattas@hotmail.com \\ Marilda da Silva \\ Universidade Estadual Paulista Júlio \\ de Mesquita Filho - UNESP - Rio \\ Claro/SP - Brasil \\ marilda@fclar.unesp.br
}

\section{Para citar este artigo:}

TANNURI, João Guilherme de Carvalho Gattás; SILVA, Marilda da. Família homoparental: enfrentando a vitalidade do patriarcado. Revista Linhas. Florianópolis, v. 20, n. 43, p. 256-271, maio/ago. 2019. 


\title{
Homosexual family: facing the vitality of patriarchy
}

\begin{abstract}
We describe the development of homoparental family in Brazil in confrontation with the preservation and conservation of patriarchy culturally installed since the discovery of the country. We prioritize research and Brazilian statistical data as structuring elements of the respective description. This is a bibliographical research with a qualitative approach. The sources are 25 documents produced from 2009 to 2015. The data relate to: the setting that preceded the homoparental family, a scenario of violence on which the homoparental family is based, and some incursions about the school's contribution to the production of prejudices and the preservation of patriarchy. Thus, and in this case, despite the legal advances indicating the construction of a fair and egalitarian social coexistence environment for homoaffective people and homoparental families, Brazilian society is far, in fact and law, operating them. The hegemony is still patriarchy, but its vitality is also being tested.
\end{abstract}

Keywords: Patriarchy. Homosexual Family. Violence. School. 


\section{Introdução}

Mostra-se neste artigo $^{1}$ o desenvolvimento da família homoparental no Brasil a partir do confronto que se estabelece com a conservação do patriarcado culturalmente instalado em nosso país desde seu descobrimento. Portanto, priorizaram-se pesquisas e dados estatísticos brasileiros como elementos estruturadores da respectiva descrição. Trata-se de uma pesquisa bibliográfica realizada nos seguintes bancos de dados: Capes (Coordenação de Aperfeiçoamento de Pessoal de Nível Superior), Scielo (Scientific Electronic Library Online), bibliotecas das universidades do Estado de São Paulo, como Unicamp (Universidade de Campinas), USP (Universidade de São Paulo), Unesp (Universidade Estadual Paulista), Ufscar (Universidade Federal de São Carlos) e Unifesp (Universidade Federal do Estado de São Paulo). O período de produção compreende os anos de 2009 a $2015^{2}$. Os descritores "família homoparental" e "escola e filhos de homoafetivos" orientaram a busca que resultou em 54 obras, das quais selecionamos 25 que atendem o objetivo desta pesquisa. Elas estão distribuídas do seguinte modo: 11 artigos, quatro dissertações, duas teses, cinco pesquisas em âmbito nacional e três livros cuja hegemonia é da análise teórica sobre a temática.

De tais fontes, extraímos as informações que nos permitiram organizar a descrição que apresentaremos aqui, que se referem: à ambientação que antecedeu a família homoparental de fato e de direito, ao cenário de violência no qual se assenta a família homoparental no Brasil e a algumas incursões sobre a contribuição da escola na produção de preconceitos e na conservação do patriarcado. Esse entrelaçamento levou-nos à assertiva: o desenvolvimento da família homoparental é mais um obstáculo à vitalidade do patriarcado instalado em nosso país, que se renova sem dissimulação e também com dissimulação por meio do mito fundador, bem como da constituição da nação, há mais de quinhentos anos (CHAUI, 2000). E encontra, a partir de 2011, um obstáculo institucional

\footnotetext{
1 Este artigo deriva da dissertação intitulada $O$ que dizem famílias homoparentais sobre as relações estabelecidas com a escola de seus filhos: tensões entre aceitação e discriminação, desenvolvida no Programa de Pós-Graduação em Educação do Instituto de Biociências da Universidade Estadual Paulista "Júlio de Mesquita Filho" - campus de Rio Claro - concluída em 2017.

${ }^{2}$ Optamos por este período, pois a pesquisa de Mestrado originou-se de um trabalho de Iniciação Científica intitulado: A violência em espaço escolar produzida no contexto francês: em pesquisas francesas (2009-2013). Assim, aproveitamos o recorte anteriormente utilizado e acrescentamos dois anos para que pudéssemos compreender o que pesquisas brasileiras, concluídas até o ano de 2015, diziam a respeito da família homoparental no Brasil e as respectivas relações com instituições escolares de nosso país.
} 
que constitui o marco regulatório que dá abertura às uniões entre pares de mesmo sexo, o que contraria frontalmente a constituição da família heteroparental, ou tradicional, que é o suporte básico do patriarcado.

Como afirmam Narvaz e Koller (2006), diferentes estudos antropológicos apreendem que as primeiras sociedades - ditas primitivas - organizavam-se a partir da relevante contribuição das mulheres. Essas antigas sociedades dividiam-se em organizações matrilineares, nômades, tribais e/ou coletivistas cuja participação da mulher nas atividades cotidianas não se restringia às diferenças sexuais. Acreditava-se que a descendência principal entre os membros advinha da figura materna, devido ao desconhecimento sobre a participação do homem na reprodução biológica. Sendo assim, o patriarcado só vai se constituir a partir da compreensão sobre a influência do homem na reprodução biológica (SAFFIOTI, 2004). Mais tardiamente, o patriarcado propagou-se fundamentado pelos valores da propriedade privada. As uniões afetivas tornaram-se predominantemente monogâmicas, tendo em vista a herança de riquezas aos descendentes legítimos. O acirramento da divisão dos gêneros - feminino e masculino atingiu a liberdade do corpo e da sexualidade das mulheres, tolhendo-as dos mesmos direitos que os homens. Com a expansão do sistema capitalista, houve a inserção das mulheres no mercado de trabalho e as disparidades em comparação aos homens se alargaram em muitos sentidos. O patriarcado segue, então, conservando os direitos sexuais para os homens e os deveres impostos à constituição das famílias heteroparentais.

\section{As fontes}

A seguir, encontra-se detalhadamente no Quadro 1, o conjunto de pesquisas com o qual trabalhamos.

\section{Quadro 1 - A família homoparental em questão}

\begin{tabular}{|l|l|l|l|}
\hline Ano & Título da Pesquisa & Autor & Modalidade \\
\hline 2009 & $\begin{array}{l}\text { Homoafetividade na escola: a } \\
\text { diferença emancipatória do } \\
\text { direito }\end{array}$ & Elias Mugrabi & Artigo \\
\hline 2010 & $\begin{array}{l}\text { Desconstruindo preconceitos } \\
\text { sobre a homoparentalidade }\end{array}$ & $\begin{array}{l}\text { Jorge Gato; Anne } \\
\text { Marie Fontaine }\end{array}$ & Artigo \\
\hline
\end{tabular}




\begin{tabular}{|c|c|c|c|}
\hline 2011 & $\begin{array}{l}\text { Impacto da orientação sexual } \\
\text { e do género na parentalidade: } \\
\text { uma revisão dos estudos } \\
\text { empíricos com famílias } \\
\text { homoparentais }\end{array}$ & $\begin{array}{l}\text { Jorge Gato; Anne } \\
\text { Marie Fontaine }\end{array}$ & Artigo \\
\hline 2011 & $\begin{array}{l}\text { O tema da homofobia em } \\
\text { dissertações e teses }\end{array}$ & 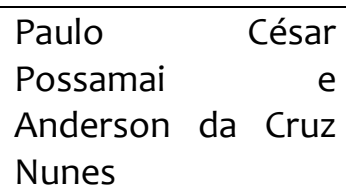 & Artigo \\
\hline 2011 & $\begin{array}{l}\text { "Querem, na escola, } \\
\text { transformar seu filho de } 6 \text { a } 8 \\
\text { anos em homossexual": } \\
\text { Sexualidade, educação e a } \\
\text { potência do discurso } \\
\text { heteronormativo }\end{array}$ & $\begin{array}{lr}\text { Carla } & \text { Lisbôa } \\
\text { Grespan e } & \text { Silvana } \\
\text { Vilodre Goellner }\end{array}$ & Artigo \\
\hline 2011 & $\begin{array}{l}\text { Homofobia e educação: } \\
\text { quando a omissão também é } \\
\text { signo de violência }\end{array}$ & $\begin{array}{l}\text { Nilson Fernandes } \\
\text { Dinis }\end{array}$ & Artigo \\
\hline 2011 & $\begin{array}{l}\text { A experiência da maternidade } \\
\text { em uma família homoafetiva } \\
\text { feminina }\end{array}$ & $\begin{array}{l}\text { Ana Laura Moraes } \\
\text { Martinez e } \\
\text { Valéria Barbieri }\end{array}$ & Artigo \\
\hline 2012 & $\begin{array}{l}\text { Da realização do projeto } \\
\text { homoparental em face à } \\
\text { vulnerabilidade das crianças } \\
\text { envolvidas }\end{array}$ & $\begin{array}{l}\text { Valéria Silvia } \\
\text { Galdino Cardin; } \\
\text { Leticia Carla } \\
\text { Baptista Rosa } \\
\end{array}$ & Artigo \\
\hline 2013 & $\begin{array}{l}\text { A resolução n. } 175 \text { do CNJ e a } \\
\text { celebração do casamento }\end{array}$ & $\begin{array}{l}\text { Valmir César } \\
\text { Pozzetti; Urbanete } \\
\text { de Angiolis Silva }\end{array}$ & Artigo \\
\hline 2014 & $\begin{array}{l}\text { O respeito à diversidade e a } \\
\text { formação social do indivíduo: } \\
\text { uma análise do bullying } \\
\text { sofrido por crianças advindas } \\
\text { de famílias homoafetivas }\end{array}$ & $\begin{array}{l}\text { Jackelline Fraga } \\
\text { Pessanha' Marcelo } \\
\text { Sant'Anna Vieira } \\
\text { Gomes }\end{array}$ & Artigo \\
\hline 2015 & $\begin{array}{l}\text { Homofobia e heterossexismo } \\
\text { nas escolas: propostas } \\
\text { pedagógicas inclusivas }\end{array}$ & $\begin{array}{l}\text { Ednildon Ramalho } \\
\text { Fideles Júnior }\end{array}$ & Artigo \\
\hline 2011 & $\begin{array}{l}\text { Homoparentalidade: estudo } \\
\text { psicanalítico sobre papéis e } \\
\text { funções parentais em casais } \\
\text { homossexuais com filhos }\end{array}$ & $\begin{array}{l}\text { Ricardo de Souza } \\
\text { Vieira }\end{array}$ & Dissertação \\
\hline 2012 & $\begin{array}{l}\text { A representação parental de } \\
\text { casais homossexuais } \\
\text { masculinos }\end{array}$ & $\begin{array}{l}\text { Brunella Carla } \\
\text { Rodriguez }\end{array}$ & Dissertação \\
\hline 2012 & $\begin{array}{l}\text { Relação Escola e famílias } \\
\text { homoafetivas: visão de } \\
\text { discentes de licenciatura em } \\
\text { pedagogia }\end{array}$ & $\begin{array}{l}\text { Carmedite Moreira } \\
\text { Santos Silva }\end{array}$ & Dissertação \\
\hline 2014 & $\begin{array}{l}\text { Desvelando a família } \\
\text { homoparental: um estudo } \\
\text { sobre os relatos de casais }\end{array}$ & $\begin{array}{l}\text { Mário Augusto } \\
\text { Tombolato }\end{array}$ & Dissertação \\
\hline
\end{tabular}




\begin{tabular}{|c|c|c|c|}
\hline & homossexuais com filhos & & \\
\hline 2012 & $\begin{array}{l}\text { Os processos subjetivos no } \\
\text { acolhimento e na adoção de } \\
\text { crianças por casal } \\
\text { homoafetivo: um estudo de } \\
\text { caso }\end{array}$ & $\begin{array}{l}\text { Maurício Ribeiro de } \\
\text { Almeida }\end{array}$ & Tese \\
\hline 2012 & $\begin{array}{l}\text { Duas mães? Mulheres lésbicas } \\
\text { e maternidade }\end{array}$ & $\begin{array}{l}\text { Maria Eduarda } \\
\text { Cavadinha Corrêa }\end{array}$ & Tese \\
\hline 2009 & $\begin{array}{l}\text { Pesquisa sobre preconceito e } \\
\text { discriminação em âmbito } \\
\text { escolar }\end{array}$ & $\begin{array}{l}\text { Instituto Nacional } \\
\text { de Estudos e } \\
\text { Pesquisa } \\
\text { Educacionais (INEP) }\end{array}$ & $\begin{array}{l}\text { Pesquisa em } \\
\text { âmbito } \\
\text { nacional }\end{array}$ \\
\hline 2009 & $\begin{array}{l}\text { Projeto de estudo sobre } \\
\text { ações discriminatórias no } \\
\text { âmbito escolar, organizadas } \\
\text { de acordo com áreas } \\
\text { temáticas, a saber, étnico- } \\
\text { racial, gênero, geracional, } \\
\text { territorial, necessidades } \\
\text { especiais, socioeconômica e } \\
\text { orientação sexual: relatório } \\
\text { final }\end{array}$ & $\begin{array}{l}\text { Instituto Nacional } \\
\text { de Estudos e } \\
\text { Pesquisa } \\
\text { Educacionais } \\
\text { (INEP); Fundação } \\
\text { Instituto de } \\
\text { Pesquisas } \\
\text { Econômicas (FIPE) }\end{array}$ & $\begin{array}{l}\text { Pesquisa em } \\
\text { âmbito } \\
\text { nacional }\end{array}$ \\
\hline 2013 & $\begin{array}{llr}\text { Relatório } & \text { de } & \text { violência } \\
\text { homofóbica } & \text { no } & \text { Brasil: ano } \\
2013 & & \end{array}$ & $\begin{array}{l}\text { Secretaria Especial } \\
\text { de Direitos } \\
\text { Humanos do } \\
\text { Ministério das } \\
\text { Mulheres, da } \\
\text { Igualdade Racial e } \\
\text { dos Direitos } \\
\text { Humanos - Brasil }\end{array}$ & $\begin{array}{l}\text { Pesquisa em } \\
\text { âmbito } \\
\text { nacional }\end{array}$ \\
\hline 2014 & Estatística do Registro Civil & $\begin{array}{l}\text { Instituto Brasileiro } \\
\text { de Geografia e } \\
\text { Estatística (IBGE) }\end{array}$ & $\begin{array}{l}\text { Pesquisa em } \\
\text { âmbito } \\
\text { nacional }\end{array}$ \\
\hline 2014 & $\begin{array}{l}\text { Assassinato de homossexuais } \\
\text { (LGBT) no Brasil: relatório } \\
2014\end{array}$ & $\begin{array}{l}\text { Grupo Gay da Bahia } \\
\text { (GGB) }\end{array}$ & $\begin{array}{l}\text { Pesquisa em } \\
\text { âmbito } \\
\text { nacional }\end{array}$ \\
\hline 2013 & $\begin{array}{l}\text { Manual da Homoafetividade: } \\
\text { da possibilidade jurídica do } \\
\text { casamento civil, união estável } \\
\text { e da adoção por casais } \\
\text { homoafetivos }\end{array}$ & $\begin{array}{l}\text { Paulo Roberto lotti } \\
\text { Vecchiatti }\end{array}$ & Livro \\
\hline 2009 & $\begin{array}{l}\text { A adoção por homossexuais: } \\
\text { a família homoparental sob o } \\
\text { olhar da psicologia jurídica }\end{array}$ & $\begin{array}{l}\text { Mariana de Oliveira } \\
\text { Farias e Ana Cláudia } \\
\text { Bortolozzi Maia } \\
\end{array}$ & Livro \\
\hline 2010 & $\begin{array}{l}\text { Homofobia: história e crítica } \\
\text { de um preconceito }\end{array}$ & Daniel Borrillo & Livro \\
\hline
\end{tabular}

Fonte: Elaboração própria, 2017. 


\section{O feminismo como ambientação inicial da família homoparental}

A respeito da trajetória da família homoparental, Roudinesco (2003) afirma que a luta desse arranjo familiar - visando colocar-se no ocidente com legitimidade social avançou em meados do século passado em alguns países da Europa e, principalmente, nos Estados Unidos da América por meio da contribuição de movimentos ativistas a favor da igualdade de direitos de pessoas homoafetivas. Os movimentos que incentivaram a visibilidade da população LGBTT (Gays, Lésbicas, Bissexuais, Travestis e Transgêneros) sofreu grande influência de adeptos do feminismo. Como já se sabe, as manifestações feministas ocorreram timidamente na primeira metade do século $X X$, atingindo seu apogeu na segunda metade desse século. Duas de suas bandeiras, nem mais nem menos importantes para o movimento do que as outras, são as que dizem respeito ao direito à igualdade de inserção aos diferentes nichos do mercado de trabalho destinados, até então, somente aos homens e a equiparação dos salários para homens e mulheres. Desde já, tais direitos até hoje, no Brasil, não estão devidamente "concedidos". Talvez, porque foram e são fortes obstáculos à respectiva esfera do patriarcado. Mas, sem sombra de dúvidas, o feminismo abriu fissuras na estrutura do patriarcado, servindo de entrada para o estabelecimento da família homoparental.

Nesse sentido, Almeida (2012) e Tombolato (2014) afirmam que os ideais feministas igualmente contribuíram para uma sociedade mais justa e igualitária no tocante às questões de gênero. Vale destacar que o movimento feminista nos anos de 1960 reivindicava o direito à liberdade sexual fora da estrutura nupcial, trazendo implicações à estrutura do casamento heterossexual da época. Já na década de 1970, o importante avanço para a liberdade da mulher foi auferido com a possibilidade do divórcio. E, a partir de então, garantiu-se que a mulher dominasse a dinâmica de sua vida amorosa e sexual, podendo desfazer-se, conforme sua vontade, de relações abusivas e/ou violentas. Ainda que julgadas preconceituosamente pela sociedade da época, a pressão do feminismo contra os respectivos valores logrou um refreamento de atitudes machistas no âmbito da vida amorosa das pessoas (CORRÊA, 2012). Por conseguinte, o surgimento da pílula anticoncepcional abalou o valor sagrado da maternidade, levando as mulheres a terem controle sobre seus corpos e, consequentemente, sobre a gravidez. $O$ feminismo contribuiu, assim, para a liberdade da expressão sexual da mulher como um 
todo até meados dos anos de 1980. A partir de então, o debate feminista foi alargado, incluindo a hierarquização dos relacionamentos amorosos, com vistas à proteção da mulher contra a violência doméstica e a justa punição dos agressores nesses casos.

Tal debate é de extrema relevância em nossa sociedade, pois o Brasil lidera o ranking mundial de violência doméstica contra mulheres. Conforme a pesquisa intitulada Mapa da Violência de 2015 (WAISELFISZ, 2015), somente no ano de 2013, 4.762 mulheres brasileiras morreram assassinadas. Não obstante, tal contingente torna-se ainda mais assustador por evidenciar que 1.583 dos crimes são tipificados como passionais, isto é, quando são realizados pelos parceiros ou ex-parceiros amorosos das vítimas. Por mais que esses dados nos façam refletir sobre a vulnerabilidade das mulheres em nossa sociedade, temos de admitir que a luta feminista impulsionou mudanças de valores e hábitos culturais na questão da sexualidade antes restritos unicamente à seara masculina (ROUDINESCO, 2003). Em suma, o feminismo no mundo ocidental promoveu o dinamismo necessário para que movimentos sociais em favor da liberdade entre pessoas homossexuais experimentassem, no final da década de 1980 e começo dos anos de 1990, suas condições afetivo-sexuais de forma menos reprimida (MARTINEZ; BARBIERI, 2011). É nessa medida que acreditamos que a família homoparental teve sua ambientação inicial no seio do feminismo.

\section{A institucionalização da família homoparental no Brasil}

O reconhecimento das relações homoafetivas tomou a mesma direção libertária no âmbito dos direitos e da aceitação sociocultural que o movimento feminista (FARIAS; MAIA, 2009). As organizações de apoio às pessoas homoafetivas intensificaram pressões por políticas isonômicas em inúmeros países. A busca pela equivalência nas instâncias jurídicas iniciou-se em meados dos anos 2000 em países desenvolvidos da América do Norte e em alguns da Europa. No que concerne à América do Sul, a Argentina foi pioneira, aprovando a união entre pessoas de mesmo sexo no ano de 2010. No Brasil, têm-se dois marcos importantes: o primeiro consta em 05 de maio de 2011, quando o Supremo Tribunal Federal reconheceu a união estável e o casamento civil entre homoafetivos, estendendo e garantindo ao companheiro (a) assistência médica, pensão alimentícia e 
direito à herança. Todavia, garantidos tais avanços, guardava-se diferença em comparação aos pares heterossexuais. Essas diferenças intervinham na realidade cotidiana de cidadãos homossexuais em união, como a dificuldade que encontravam os casais para trocar de sobrenomes. Outra diferença ainda guardada dizia respeito ao fato de o estado civil, no documento de ambos, permanecer como solteiros (as). Essa situação exigia a comprovação da união do casal por outros meios que não pela apresentação dos documentos pessoais, o que, em alguns casos, gerava situações constrangedoras.

Desenvolveram-se nos anos seguintes a discussão e o aprimoramento das leis, o que levou a novas conquistas no âmbito jurídico. Em 14 de maio de 2013, a partir da Resolução $n^{\circ}$ 175, o Conselho Nacional de Justiça exigiu obrigatoriedade de efetivação da união estável, bem como da conversão em casamento civil, em todo cartório do território nacional. Desta vez, possibilitou-se definitivamente ao casal o direito de assumir o sobrenome um do outro, de forma então, que pudessem mudar seu estado civil para casados (as) nos documentos. Nessa perspectiva, a família homoafetiva que recentemente pôde se casar, agora, está assistida por leis e amparada institucionalmente, inclusive, apta à adoção de filhos (VECCHIATTI, 2013). A partir do documento Estatísticas do Registro Civil (ESTATÍSTICAS DO REGISTRO CIVIL, 2014), desde 2011 ocorreram 4.854 uniões entre pessoas homoafetivas ${ }^{3}$. Somente entre os anos de 2013 e 2014, 1.153 casais homoafetivos realizaram legalmente suas uniões. A maioria desses casamentos foi realizada na região Sudeste $(60,3 \%)$ e a minoria na região Norte (3,4\%). Quando se compara o gênero que compõe essas uniões maritais - na forma de união estável e casamento civil -, os cônjuges masculinos são 49,7\%, enquanto os cônjuges femininos são 50,3\%. Note-se que é muito discreta a diferença entre os percentuais de famílias constituídas somente por homens e somente por mulheres.

Ademais, o que está em jogo de modo geral em nosso país é o fato de a família contemporânea ser constituída por meio de diferentes formas de composição e seus membros não corresponderem aos mesmos membros da família tradicional: pai, mãe e filhos. Os novos arranjos familiares refletem a extensão das mudanças nas relações parentais, impondo e exigindo novos conceitos e definições de família. De acordo com

\footnotetext{
${ }^{3} \mathrm{O}$ ano de publicação do referido documento é 2014. Portanto, é provável que até a publicação deste artigo o contingente de uniões entre homoafetivos/as em território nacional tenha mudado.
} 
Farias e Maia (2009), afirmamos que as relações afetivas e os sentimentos depositados nas relações familiares do presente momento projetam o significado de ser família para muito além dos enquadramentos de gênero e das questões biológico-consanguíneas. A esse respeito, Pozzetti e Silva (2013, p. 110), asseguram que

o conceito de família independe da forma como foi constituída, quer seja oriunda do casamento, da união estável, monoparental, com ou sem filhos biológicos ou adotivos, bastando que para tanto haja afinidade entre as pessoas que a constituam e que estas se considerem parentes, ainda que por vínculos unicamente de afeto.

\section{A violência herdada pela família homoparental advinda das entranhas do patriarcado}

Levando em conta que o movimento feminista ganhou maior visibilidade ao apontar a necessidade dos princípios isonômicos básicos entre mulheres e homens em diferentes espaços sociais, pode-se dizer que o feminismo constitui a ambientação inicial da família homoparental, que herdou os louros do movimento e, sobretudo, a violência direcionada a ele pela resistência do patriarcado com fortes tintas de machismo. À medida que a experimentação da liberdade sexual entre homoafetivos foi ganhando visibilidade, a violência contra eles seguiu a mesma curva ascendente que abriga as mulheres. O Brasil é o país que exibe os maiores índices de violência contra homossexuais, travestis e mulheres do mundo (GRUPO GAY DA BAHIA, 2014), contrariando os representativos avanços legais referentes às relações entre pares de mesmo sexo, bem como os avanços advindos das lutas feministas. A família homoparental ainda é, no Brasil, uma família rejeitada socioculturalmente em favor da permanência da família heteroparental. Entretanto, na contramão das expectativas conservadoras, Farias e Maia (2009), Almeida (2012) e Corrêa (2012) evidenciam que o cotidiano familiar homoparental se equivale em inúmeros aspectos ao cotidiano familiar heteroparental.

Não obstante, as segregações socioculturais permanecem latentes em nossa sociedade, desprestigiando a homoparentalidade. A intolerância sexual constitui um fenômeno crônico em nosso país e vincula-se intrinsecamente a questões culturais, que 
abarcam as raízes religiosas e as idealizações sobre as relações amorosas. Igualmente, tal intolerância integra o mito entre masculino/feminino - macho/fêmea - e, a partir da perspectiva da procriação, legitima o preconceito e a estranheza às relações que fujam da condição "natural" dos corpos, pois dois homens ou duas mulheres em união não fecundam e não podem procriar. Dessa maneira, cristaliza-se a associação da parentalidade vinculada unicamente às relações heterossexuais. Por conseguinte, ampliase o preconceito cultural das diferentes expressões de relacionamentos afetivos e sexuais presentes na sociedade e, consequentemente, replica-se o preconceito à homoparentalidade. Denominam-se tais manifestações de homofobia, que segundo Borrillo (2010, p. 13) constitui qualquer "atitude hostil contra as/os homossexuais; portanto homens ou mulheres". Conforme pesquisa realizada pelo Grupo Gay da Bahia (2014) foram mortos 326 homoafetivos no ano de 2014: 163 gays, 134 travestis, 14 lésbicas, 3 bissexuais e 7 pessoas amantes de travestis. Em 2015, ocorreram 318 mortes por crime de homofobia. E essa violência inicia-se muitas vezes no espaço escolar em forma de bullying contra crianças com posturas mais afeminadas/emasculadas ou adolescentes trans/homossexualmente assumidos (PESSANHA; GOMES, 2014).

Contudo, a composição da família brasileira não se modificou somente devido ao avanço e desenvolvimento da família homoafetiva. Segundo o Instituto Brasileiro de Geografia e Estatísticas (ESTATÍSTICAS DO REGISTRO CIVIL, 2014), apenas 49,9\% dos lares brasileiros é constituído pelo modelo tradicional de família, aquele composto unicamente por mães, pais e filhos. A porcentagem restante, 50,1\%, é constituída por famílias recompostas: aquelas com diferentes graus de parentesco. Também é preciso levar em conta que a família dita tradicional e/ou padrão não escapa a preconceitos. Porém, as formas de violência que atingem seus membros não dizem respeito necessariamente às questões da sexualidade, mas, ao racismo, xenofobia, classe social etc. (ROUDINESCO, 2003). A respeito do preconceito devido à classe social temos as denominações: famílias recompostas e/ou famílias desestruturadas. A última denominação diz-se para quando se trata daquelas pertencentes às classes populares. E quando se trata de frações abastadas, as famílias de arranjos diferentes ao tradicional são consideradas 'recompostas', apenas (ABADE, 2014). Portanto, "não há o que comemorar", como disse 
Chauí (2000, p. 95) acerca dos preconceitos e violências perpetrados em nosso país desde o seu descobrimento.

\section{Considerações finais}

As segregações dos gêneros se instauram culturalmente na sociedade desde a infância com a participação efetiva da escola que não se furta ao reflexo cultural da sociedade. Tais segregações são estruturadas na escola e na vida cotidiana, por exemplo, por meio do azul da bola do menino e do rosa da boneca da menina. Nas creches que organizam pedagogicamente os ambientes do brincar com jogos para meninos e meninas, com brincadeiras cujo conteúdo tem endereço certo: reprodução de papéis sociais do homem e reprodução de papéis sociais da mulher. Contudo, desde os últimos Parâmetros Curriculares Nacionais (BRASIL, 1998) para a Educação Básica em nosso país, que datam de 1998, a temática sexualidade/gênero vem figurando como um conteúdo curricular com vistas a arejar práticas curriculares e escolares, cujo fim é a erradicação de preconceitos operacionalizados nessa instituição que dizem respeito a essa temática (GONÇALVES, SPOSITO, 2002; BRASIL, 2009; FIDELES JÚNIOR, 2015; MUGRABI, 2009). Assim, é válido ressaltar que a escola produz o preconceito em questão, mas também busca alternativas para combatê-lo.

Se as divisões entre os sexos ainda ocorrem nas escolas, elas se repetem no seio familiar. Em nossas fontes há inúmeros relatos dramáticos de pessoas homoafetivas que foram expulsas de seus lares ou sofreram forte repreensão/repulsa por seus próprios pais e parentes próximos. A assunção da homo/trans/bissexualidade para as famílias costuma ser um episódio doloroso na vida dessas pessoas, como observa Tombolato (2014). É a hegemonia do patriarcado, por assim dizer, que está em cheque. Contudo, tal situação também leva a uma revisão dos laços afetivos que unem as pessoas enquanto familiares, principalmente dos parentes próximos como pais, mães e irmãos.

Nessa medida, é do patriarcado que vem os instrumentos de intimidação da pluralidade sexual. Por exemplo, pessoas do sexo masculino ao assumirem sua condição homoafetiva tendem a sofrer maior discriminação de suas famílias do que em comparação a pessoas do sexo feminino. Isso se deve ao constructo machista da sociedade em geral. Desde pequenos, os meninos estão expostos ao retraimento de 
gestos e atitudes delicadas, pois se aproximar de sentimentos ditos femininos seria estar em desvantagem no patriarcado. Por conseguinte, as mulheres são inferiorizadas em diversos setores sociais em que os homens desfrutam de privilégios e tal fato propicia atitudes de poder que, em muitos casos, resultam em violência. Conforme o documento Mapa da Violência (2015) são sete mulheres mortas por crimes passionais por dia. Tais contingentes são preocupantes quando levamos em conta todos os marcos institucionalmente instaurados desde 1980 até nossos dias, cujos objetivos são destinados à proteção da mulher e dos homossexuais de modo geral.

Assim, e neste caso, apesar dos avanços legais indicarem a construção de um ambiente de convivência social justo e igualitário para as pessoas homoafetivas e para as famílias homoparentais, a sociedade brasileira está longe de operacionalizá-los de fato e de direito. Em muitos sentidos, em nossa sociedade, os valores do patriarcado ainda são hegemônicos, mas sua vitalidade está sendo colocada à prova.

\section{Referências}

ABADE, Flavia. Famílias patrifocais: paternagem e socialização dos filhos. Dissertação (Mestrado em Psicologia), Universidade de São Paulo, Ribeirão Preto, 2014.

ALMEIDA, Maurício Ribeiro de. Os processos subjetivos no acolhimento e na adoção de crianças por casal homoafetivo: um estudo de caso. 2012. Tese (Doutorado em Psicologia Social) - Instituto de Psicologia, Universidade de São Paulo, São Paulo, 2012.

BORRILLO, Daniel. Homofobia: história e crítica de um preconceito. Belo Horizonte: Autêntica Editora, 2010.

BRASIL. Ministério da Educação; Instituto Nacional de Estudos e Pesquisas Educacionais; Fundação Instituto de Pesquisas Econômicas. Projeto de estudo sobre ações discriminatórias no âmbito escolar, organizadas de acordo com áreas temáticas, a saber, étnico-racial, gênero, geracional, territorial, necessidades especiais, socioeconômica e orientação sexual. Brasília, DF, 2009. Disponível em: <http://portal.mec.gov.br/ dmdocuments/relatoriofinal.pdf >. Acesso em: 03 set. 2017. 
BRASIL. Parâmetros Curriculares Nacionais: terceiro e quarto ciclos: Apresentação dos Temas Transversais. Brasília: MECSEF, 1998.

CARDIN, Valéria Silva Galdino; ROSA, Letícia Carla Baptista. Da realização do projeto homoparental em face à vulnerabilidade das crianças envolvidas. Revista Jurídica, Curitiba, v. 1, n. 28, p. 230-252, jun. 2012. Disponível em: <http://revista.unicuritiba.edu.br/ index.php/RevJur/article/view/427/332>. Acesso em: 03 set. 2017.

CHAUÍ, Marilena. Brasil: mito fundador e sociedade autoritária. São Paulo: Fundação Perseu Abramo, 2000.

CORRÊA, Maria Eduarda Cavadinha. Duas mães? Mulheres lésbicas e maternidade. 2012. Tese (Doutorado em Saúde Materno Infantil) - Faculdade de Saúde pública, Universidade de são Paulo, São Paulo, 2012.

DINIS, Nilson Fernandes. Homofobia e educação: quando a omissão também é signo de violência. Educ. rev., Curitiba, n. 39, p. 39-50, abr. 2011. Disponível em: $<$ http://www.scielo.br/scielo.php?script=sci_arttext\&pid=S0104-40602011000100004\& lng=pt\&nrm=iso $>$. Acesso em: 03 set. 2017.

ESTATÍSTICAS DO REGISTRO CIVIL. Rio de Janeiro: IBGE, v.41, p.1- 82, 2014. Disponível em: <http://www.ibge.gov.br/home/estatistica/populacao/registrocivil/2014/>. Acesso em: 03 set. 2017.

FARIAS, Mariana. Oliveira.; MAIA, Ana, Carolina. Bortolozzi. Adoção por homossexuais: a família homoparental sob o olhar da psicologia jurídica. Curitiba: Juruá, 2009.

FIDELES JÚNIOR, Ednildon Ramalho. Homofobia e heterossexismo nas escolas: propostas pedagógicas inclusivas. Gênero e sexualidade, Campina Grande, 2015. Disponível em: <http://www.editorarealize.com.br/revistas/generoxi/trabalhos/TRABALHO_EVo46_MD1_ SA2_ID301_29042015004224.pdf>. Acesso em: 03 set. 2017.

GATO, Jorge; FONTAINE, Anne Marie. Desconstruindo preconceitos sobre a homoparentalidade. Les Online, v. 2, n. 2, p. 14-21, 2010. Disponível em:

<http://www.lespt.org/lesonline/index.php?journal=lo\&page=article\&op=viewArticle\&pat h;[]=34>. Acesso em: 03 set. 2017.

GATO, Jorge; FONTAINE, Anne Marie. Impacto da orientação sexual e do género na parentalidade: uma revisão dos estudos empíricos com famílias homoparentais. Ex aequo, Vila Franca de Xira, n. 23, 2011. Disponível em: <http://www.scielo.mec.pt/ scielo.php?script=sci_arttext\&pid=S0874-55602011000100008\&lng=pt\&nrm=iso $>$. Acesso em: 03 set. 2017.

GRESPAN, Carla Lisbôa; GOELLNER, Silvana Vilodre. "Querem, na escola, transformar seu filho de 6 a 8 anos em homossexual": sexualidade, educação e a potência do discurso heteronormativo. Entreideias: Educação, cultura e sociedade, Salvador, v. 19, p. 103-122, jun. 2011. Disponível em: 
<http://www.portalseer.ufba.br/index.php/entreideias/article/view/ 5251/4303>. Acesso em: 03 set. 2017.

GRUPO GAY DA BAHIA. Assassinato de homossexuais (LGBT) no Brasil: relatório 2014. Salvador: Editora Grupo Gay da Bahia, 2014.

GONÇALVES, Luis Alberto Oliveira; SPOSITO, Marilia Pontes. Iniciativas públicas de redução da violência escolar no Brasil. Cadernos de Pesquisa, São Paulo, n. 115, p. 101-138, 2002.

MARTINEZ, Ana Laura Moraes; BARBIERI, Valéria. A experiência da maternidade em uma família homoafetiva feminina. Estudos de Psicologia, Campinas, v. 28, n. 2, p.175-185, jun. 2011. FapUNIFESP (SciELO). DOI: 10.1590/s0103-166x2011000200005. Disponível em: <http://www.scielo.br/scielo.php?script=sci_arttext\&pid=S0103-166X2011000200005\& Ing=pt\&nrm=iso\&tlng=p>t. Acesso em: 03 set. 2017.

MUGRABI, Elias. Homoafetividade na Escola: a diferença Emancipatória do Direito. Intertemas, Presidente Prudente, v. 14, p. 114-138, nov. 2009. Disponível em: <http://intertemas.unitoledo.br/revista/index.php/INTERTEMAS/article/view/2734>. Acesso em: 03 set. 2017.

NARVAZ, Martha Giudice; KOLLER, Sílvia Helena. Famílias e patriarcado: da prescrição normativa à subversão criativa. Psicol. Soc., Porto Alegre, v. 18, n. 1, p. 49-55, abril de 2006. Disponível em: <http://www.scielo.br/scielo.php?script=sci_arttext\&pid=S010271822006000100007\&lng=pt_BR\&nrm=iso>. Acesso em: 03 set. 2017.

PESSANHA, Jackelline Fraga; GOMES, Marcelo Sant'anna Vieira. O respeito à diversidade e a formação social do indivíduo: uma análise do bullying sofrido por crianças advindas de famílias homoafetivas. Opinión Jurídica, Medellín, v. 13, n. 25, p. 51-67, abr. 2014. Disponível em: <http://www.scielo.org.co/scielo.php?script=sci_arttext\&pid=S1692$25302014000100004>$. Acesso em: 03 set. 2017.

POSSAMAI, Paulo César; NUNES, Anderson da Cruz. O tema da homofobia em dissertações e teses. MÉTIS: história \& cultura, Caxias do Sul, v. 10, n. 20, p. 273-284, dez. 2011. Disponível em:

<http://www.ucs.br/etc/revistas/index.php/metis/article/viewArticle/1341>. Acesso em: 03 set. 2017.

POZZETTI, Valmir César; SILVA, Urbanete de Angiolis. A resolução n. 175 do CNJ e os requisitos para a celebração do casamento. Scientia luris, Londrina, v. 17, n. 2, p. 107-130, dez. 2013.

RODRIGUEZ, Brunella. Carla. A representação parental de casais homossexuais masculinos. 2012. Dissertação (Mestrado em Psicologia Clínica) - Instituto de Psicologia, Universidade de São Paulo, São Paulo, 2012. Disponível em: <http://www.teses.usp.br/ teses/disponiveis/47/471333/tde-07022013-092525/>. Acesso em: 03 set. 2017. 
ROUDINESCO, Elisabeth. A Família em Desordem. Rio de Janeiro: Zahar, 2003.

SAFFIOTI, Heleieth I. B. Gênero, patriarcado, violência. São Paulo: Fundação Perseu Abramo, 2004.151 p.

SECRETARIA ESPECIAL DE DIREITOS HUMANOS DO MINISTÉRIO DAS MULHERES, DA IGUALDADE, RACIAL E DOS DIREITOS HUMANOS. Relatório de violência homofóbica no Brasil: ano de 2013. Brasília, 2016. Disponível em:

<http://www.sdh.gov.br/assuntos/lgbt/dados-estatisticos/Relatorio2013.pdf >. Acesso em: 03 set. 2017.

SILVA, Carmedite Moreira Santos. Relação escola e famílias homoafetivas: visão de discentes de literatura em pedagogia. 2012. Dissertação (Mestrado em Família na Sociedade Contemporânea) - Universidade Católica do Salvador, Salvador, 2012. Disponível em: <http://tede.ucsal.br/tde_busca/arquivo.php?codArquivo=305>. Acesso em: 03 set. 2017.

TOMBOLATO, Mário Augusto. Desvelando a família homoparental: um estudo sobre os relatos de casais homossexuais com filhos. 2014. 117 f. Dissertação (Mestrado em Psicologia) - Universidade Estadual Paulista “Júlio de Mesquita Filho", Faculdade de Ciências, Bauru, 2014.

VECCHIATTI, Paulo Roberto lotti. Manual de homoafetividade: da possibilidade jurídica do casamento civil, união estável e da adoção por casais homoafetivos. São Paulo: Método, 2013.

VIEIRA, Ricardo de Souza. Homoparentalidade: estudo psicanalítico sobre papéis e funções parentais em casais homossexuais com filhos. 2011. Dissertação (Mestrado em Psicologia Clínica) - Instituto de Psicologia, Universidade de São Paulo, São Paulo, 2011. Disponível em: <http://www.teses.usp.br/teses/disponiveis/47/471333/tde-19072011084912/>. Acesso em: 03 set. 2017.

WAISELFISZ, Julio Jacobo. Mapa da violência 2015: homicídio de mulheres no Brasil. Brasília, DF: FLACSO, 2015. Disponível em:

<http://www.mapadaviolencia.org.br/pdf2015/MapaViolencia_2015_mulheres.pdf>. Acesso em: 03 set. 2017.

Recebido em: 30/10/2017 Revisões requeridas: 28/09/2018 Aprovado em: $17 / 10 / 2018$

Universidade do Estado de Santa Catarina - UDESC Programa de Pós-Graduação em Educação - PPGE Revista Linhas

Volume 20 - Número 43 - Ano 2019 revistalinhas@gmail.com 